\title{
ORIGINAL ARTICLE \\ Supine and upright urodynamic evaluation of incontinent ileovesicostomy in wheelchair-bound adults with neurogenic bladder
}

\author{
M Vainrib ${ }^{1,2}$, P Reyblat ${ }^{3}$, WG Kong ${ }^{4}$ and DA Ginsberg ${ }^{1,5}$
}

\begin{abstract}
Study design: Prospective.
Objectives: To evaluate detrusor leak point pressure (DLPP) of the incontinent ileovesicostomy in the supine and upright position. Setting: California, USA.

Methods: Urodynamic assessment of patients, 6-36 months after ileovesicostomy, was performed in the supine position and then immediately repeated in the upright position in the patient's wheelchair.

Results: Upright and supine urodynamic evaluation was performed following the Good Urodynamic Practice Guidelines. Ten patients (seven male and three female) were evaluated. Etiology of neurogenic bladder (NGB) included seven patients with spinal cord injury and one patient each with multiple sclerosis, myelomeningocele and cerebral palsy. Mean DLLP in the supine position was $8.6 \mathrm{~cm} \mathrm{H}_{2} \mathrm{O}$ (range 2-20); mean DLLP in the sitting position was $11.6 \mathrm{~cm} \mathrm{H}_{2} \mathrm{O}$ (range 5-25). Mean change in DLPP from supine to sitting was $3.1 \mathrm{~cm} \mathrm{H}_{2} \mathrm{O}$ (range 1-12). The difference in DLPP between supine and sitting is statistically significant $(P=0.0429)$; however, this does not appear to be a clinically significant difference.

Conclusion: lleovesicostomy is a safe option for management of the NGB in a selected patient population. A small and clinically insignificant or no change in DLPP was documented in all ten patients. We demonstrated that DLPP remains low within an ileovesicostomy while in the sitting position.
\end{abstract}

Spinal Cord (2013) 51, 634-636; doi:10.1038/sc.2013.26; published online 16 April 2013

Keywords: ileovesicostomy; neurogenic bladder; urodynamic study; urinary diversion

\section{INTRODUCTION}

Smith and Hinman first described ileovesicostomy in 1955, using dogs and anastomosing ileum to the native bladder in situ. ${ }^{1}$ Two years later, Cordonnier described a case series of three children with neurogenic bladder (NGB) secondary to meningomyelocele on whom he utilized an 'ileocystostomy' (aka 'ileovesicostomy'). ${ }^{2}$

In more recent years, multiple authors have reported that the ileovesicostomy procedure provides an easily emptying and noncatheterizable low-pressure urinary conduit. ${ }^{3,4}$ With ileovesicostomy, the primary objectives include establishing a vesical diversion that has a low detrusor leak point pressure (DLPP) and minimal complications, thus allowing safe, lifelong, catheter-free bladder drainage. ${ }^{3}$ In addition, the native antireflux mechanism is preserved and the potential risk of ureteral-ileal anastomotic stricture after cystectomy and lower urinary tract reconstruction is eliminated.

Indications for ileovesicostomy include patients with NGB who are unable or unwilling to manage their bladder by less invasive methods, such as clean intermittent catheterization (CIC), reflex voiding to a condom catheter and/or use of an indwelling catheter. Common reasons for ileovesicostomy include patients with injuries that impact their ability to perform CIC (that is, cervical level of spinal cord injury (SCI)) combined with a variety of other issues such as severe urethral damage secondary to long-term indwelling catheter or perineal pressure ulcer eroding into the urethra. ${ }^{5}$ If the urethra is severely damaged a concomitant bladder neck closure (BNC) may be needed as well. ${ }^{6}$

The aim of urodynamics (UDS) is to make precise pressure and volume measurements, while reproducing symptoms in order to identify the underlying causes for the symptoms, and to quantify the related pathophysiological processes. ${ }^{7}$ This group of patients spends a substantial portion of their waking hours sitting in a wheelchair. We aimed to evaluate DLPP of the incontinent ileovesicostomy in the supine and sitting upright position in these patients to determine whether they have a higher DLPP when upright that could lead to future danger to their upper urinary tracts.

\section{MATERIALS AND METHODS}

We developed an Institutional review board approved, prospective evaluation of NGB patients who had prior ileovesicostomy and were followed in the urology clinic at Rancho Los Amigos National Rehabilitation Center. For the study, we were able to identify ten patients. After informed consent was signed, patient charts were reviewed and UDS performed.

All UDS were performed according to ICS guidelines. ${ }^{7}$ Initially, UDS was performed with standard technique in the supine position. The patient was then transferred into the wheelchair with the urodynamic catheters secured in place. UDS evaluation was repeated in the sitting position. DLPP was recorded

${ }^{1}$ USC Institute of Urology, University of Southern California, Los Angeles, CA, USA; ${ }^{2}$ Department of Urology, Meir Medical Center, Kfar Saba, Israel; ${ }^{3}$ Department of Urology, Kaiser Permanente Los Angeles Medical Center, Los Angeles, CA, USA; ${ }^{4}$ El Camino Urology Medical Group, Mountain View, CA, USA and ${ }^{5}$ Urology Service, Rancho Los Amigos National Rehabilitation Center, Downey, CA, USA

Correspondence: Dr M Vainrib, Department of Urology, Meir Medical Center, 59 Tchernichovsky Street, Kfar Sava 44410, Israel.

E-mail: mvainrib@gmail.com

Received 24 January 2013; revised 12 March 2013; accepted 17 March 2013; published online 16 April 2013 
and compared using student's $t$-test when the patient was in supine and sitting positions. $P<0.05$ was considered to be a significant difference.

\section{RESULTS}

Ten patients (seven male and three female) were included in the study. All had ileovesicostomy performed at Rancho Los Amigos National Rehabilitaiton Center. Demographic data is presented in Table 1. In seven of ten patients, NGB was caused by traumatic SCI, five secondary to gunshot wound. SCI level was thoracic in four patients and cervical in three. Three patients had atraumatic ethology for their NGB: multiple sclerosis_-one, myelomeningocele-one and cerebral palsy-one. Eight of ten patients underwent concomitant BNC due to a poor outlet secondary to their inherent neurologic disease or traumatic injury/urethral erosion from long-term catheter use.

Mean age at surgery was 39 (range 24-57) years old. For patients with SCI, mean time from their SCI to ileovesicostomy was 10.5 years (range 1-21 years). Mean time from surgery to UDS evaluation for all patients ranged from 6-36 months. Mean follow-up after surgery for all patients was 6.5 (range 5-8) years.

DLPP results for each individual patient are in listed in Table 1 . The mean DLLP in the supine position was $8.6 \mathrm{~cm} \mathrm{H}_{2} \mathrm{O}$ (range 2-20); mean DLLP in the sitting position was $11.6 \mathrm{~cm} \mathrm{H}_{2} \mathrm{O}$ (range 5-25). The mean change in DLPP from supine to sitting was $3.1 \mathrm{~cm} \mathrm{H}_{2} \mathrm{O}$ (range1-12). The net difference in DLPP between supine and sitting positions was $3.0 \mathrm{~cm} \mathrm{H}_{2} \mathrm{O}(P=0.0429)$.

\section{DISCUSSION}

Management of NGB can be very challenging. When deciding how to treat a patient with NGB, issues that should be addressed include the type and level of injury, type of bladder dysfunction, the patient's ability or desire to perform CIC and the cause of NGB. Options include pharmacologic treatment, indwelling catheters, reflex voiding to a condom catheter, use of diapers or pads, CIC, botulinum toxin intradetrusor injections and low urinary tract (LUT) reconstruction.

The current standard practice is an initial a trial of management with CIC for patients that are willing and able to perform catheterizataion. For many patients, however, the primary method of LUT management is indwelling urinary catheter (urethral versus suprapubic cystotomy). ${ }^{8}$ However, an indwelling catheter is associated with significant potential morbidity and includes risks of recurrent urinary tract infection, hematuria, bladder stones, vesicoureteral reflux, traumatic erosion of the urethra (in transurethral catheters) and bladder cancer. ${ }^{9-12}$

Possible operative interventions for patients that fail more conservative methods of LUT management include sphincterotomy (usually with reflex voiding to a condom catheter), cystectomy with ileal diversion, augmentation cystoplasty, with or without continent urinary stoma or ileovesicostomy. Multiple authors have suggested that in patients with severe LUT symptoms and who are unable to perform CIC and/or are refractory to medical therapy, ileovesicostomy should be the procedure of choice. Compared with ileovesicostomy other types of LUT reconstructive surgery require CIC (per native urethra or stoma). For those patients considering construction of a continent urinary stoma, it is important that they understand the possible risks including stomal stenosis, an incontinent stoma and a stoma that cannot be catheterized. Patients should understand there is up to a $20-30 \%$ risk that surgical revision will be necessary for a malfunctioning stoma. ${ }^{13}$

Incontinent reconstruction to the skin eliminates the need to perform CIC by a patient or a caregiver. Older studies often advocate the use of cystectomy and ileal conduit to treat NGB in patients who would benefit from an incontinent reconstruction. However, cystectomy is unnecessarily morbid and is often made unnecessary by ileovesicostomy. Also, the lifetime risk of ureteroileal obstruction after cystectomy is avoided with ileovesicostomy by preservation of the native ureterovesical junction. In our opinion, cystectomy/ileal loop should be preserved currently only in those patients who have a completely acontractile bladder (in which an ileovesicostomy is thought to empty poorly), obese patients with risk of poor emptying of the ileovesicostomy or in those with other bladder pathology requiring bladder removal (fistula and so on). ${ }^{4,13}$

All patients in our cohort had low-pressure bladders in both the supine and sitting positions. A net change of $3.1 \mathrm{~cm} \mathrm{H}_{2} \mathrm{O}$ (range 1-12) was noted between the two positions and was statistically significant. However, this does not appear to be clinically significant and clearly reflects low-pressure storage and emptying of the ileovesicosotmy for all patients evaluated in all positions. The mean DLPP in the sitting position was $11.6 \mathrm{~cm} \mathrm{H}_{2} \mathrm{O}$ (range 5-25), well below storage pressures that would place the patient's upper urinary tract at risk. ${ }^{14}$ McGuire et al. ${ }^{14}$ reported that ileovesicostomy maintains a DLPP $<40 \mathrm{~cm} \mathrm{H}_{2} \mathrm{O}$ pressure and preserves upper tract function as well or better than the traditional treatments of anticholinergic medications and CIC. However, certain patient population may not be able to perform

Table 1 Patients' demographic, surgery and UDS data

\begin{tabular}{|c|c|c|c|c|c|c|c|c|c|}
\hline \multirow[t]{2}{*}{ Patient. no. } & \multirow[t]{2}{*}{ Gender } & \multirow[t]{2}{*}{ NGB pathology } & \multirow[t]{2}{*}{ DOI } & \multirow[t]{2}{*}{ Level of injury } & \multirow[t]{2}{*}{ Age at surgery } & \multirow[t]{2}{*}{ Procedure } & \multicolumn{3}{|c|}{ UDS data } \\
\hline & & & & & & & DLPP supine & DLPP sitting & Net change \\
\hline 1 & M & $\mathrm{SCl}$ (GSW) & 1991 & $\mathrm{~T} 4$ & 34 & Ileovesicostomy, BNC & 7 & 9 & +2 \\
\hline 2 & $\mathrm{~F}$ & $\mathrm{SCl}$ (GSW) & 1979 & C5 & 49 & Ileovesicostomy, BNC & 12 & 12 & 0 \\
\hline 3 & $M$ & MMC & Birth & MMC & 24 & $\begin{array}{l}\text { Converted from augmentation } \\
\text { to ileovesicostomy, BNC }\end{array}$ & 4 & 7 & +3 \\
\hline 4 & $\mathrm{~F}$ & $\mathrm{CP}$ & Birth & $\mathrm{CP}$ & 40 & Ileovesicostomy, BNC & 10 & 10 & 0 \\
\hline 5 & $M$ & $\mathrm{SCl}$ (GSW) & 1986 & T10 & 29 & Ileovesicostomy, BNC & 4 & 11 & +7 \\
\hline 6 & M & SCl (GSW) & 1986 & T5 & 32 & Ileovesicostomy, BNC & 11 & 11 & 0 \\
\hline 7 & $\mathrm{~F}$ & MS & 1980 & MS & 57 & Ileovesicostomy, BNC & 20 & 25 & +5 \\
\hline 8 & M & $\mathrm{SCl}$ (Fall) & 2000 & $\mathrm{C} 2$ & 52 & Ileovesicostomy, BNC & 13 & 12 & -1 \\
\hline 9 & M & SCl (GSW) & 1998 & T6 & 43 & Ileovesicostomy & 2 & 14 & +12 \\
\hline 10 & $M$ & $\mathrm{SCl}(\mathrm{MVA})$ & 2003 & $\mathrm{C7}$ & 30 & Ileovesicostomy & 3 & 5 & +2 \\
\hline
\end{tabular}

Abbreviations: BNC, bladder neck closure; CP, cerebral palsy; DLPP, detrusor leak point pressure; DOI, date of injury; GSW, gunshot wound; F, female, M, male; MMC, myelomeningocele; MS, multiple sclerosis; MVA, motor vehicle accident; NGB, neurogenic bladder; $\mathrm{SCI}$, spinal cord injury; UDS, urodynamic study. 
CIC or may need to abandon CIC for a variety of reasons. In a longterm study, Leng evaluated patients yearly with UDS; DLPP $<40 \mathrm{~cm}$ $\mathrm{H}_{2} \mathrm{O}$ pressure were achieved in 38 patients $(93 \%) .{ }^{15}$

In our study, cohort patients with poor outlets were treated with concomitant BNC that minimized the associated problems with urinary incontinence secondary to an incompetent outlet. Several other groups have reported BNC outcomes in different populations. Other series of pediatric patients showed urethral leakage rates between 0 and $24 \% .^{16-18}$ In a series of 50 adult patients with NGB, Tan et al. ${ }^{19}$ noted a $72 \%$ urethral continence rate following ileovesicostomy with mean follow-up of 26.3 months. Eighty percent of those patients had some type of procedure for their outlet (that is, sling, $\mathrm{BNC}$ or urethral closure) at the time of ileovesicostomy. In a series of 23 patients with NGB that underwent ileovesicostomy, Schwartz et al. $^{20}$ reported that the creation of a low-pressure system could eliminate the associated problems with urinary incontinence, infection, calculi and urethrocutaneous fistulae.

When used appropriately, treatment of NGB can lead to significant improvements in urinary continence, protection of the upper urinary tracts, improved quality of life, and patient independence.

\section{CONCLUSIONS}

Ileovesicostomy is a safe option for management of the NGB in a selected patient population. Small and clinically insignificant change in DLPP was documented in all the ten patients. We demonstrated that detrusor pressure remains low within an ileovesicostomy while in the sitting position.

\section{DATA ARCHIVING}

There were no data to deposit.

\section{CONFLICT OF INTEREST}

The authors declare no conflict of interest.

\section{ACKNOWLEDGEMENTS}

The work was performed at Rancho Los Amigos Rehabilitation Center, Downey, CA.
1 Smith GI, Hinman Jr F. The intussuscepted ileal cystostomy. J Urol 1955; 73 261-269.

2 Cordonnier JJ. lleocystostomy for neurogenic bladder. J Urol 1957; 78 605-610.

3 Gauthier Jr AR, Winters JC. Incontinent ileovesicostomy in the management of neurogenic bladder dysfunction. Neurourol Urodyn 2003; 22: 142-146.

4 Atan A, Konety BR, Nangia A, Chancellor MB. Advantages and risks of ileovesicostomy for the management of neuropathic bladder. Urology 1999; 54: 636-640.

5 Secrest CL, Madjar S, Sharma AK, Covington-Nichols C. Urethral reconstruction in spinal cord injury patients. J Urol 2003; 170: 1217-1221.

6 Sahadevan K, Pickard RS, Neal DE, Hasan TS. Is continent diversion using the Mitrofanoff principle a viable long-term option for adults requiring bladder replacement? BJU Int 2008; 102: 236-240.

7 Schäfer W, Abrams P, Liao L, Mattiasson A, Pesce F, Spangberg A et al. International Continence Society. Good urodynamic practices: uroflowmetry, filling cystometry, and pressure-flow studies. Neurourol Urodyn 2002; 21: 261-274.

8 Cameron AP, Wallner LP, Tate DG, Sarma AV, Rodriguez GM, Clemens JQ. Bladder management after spinal cord injury in the United States 1972 to 2005. J Urol 2010, 184: 213-217 (e-pub 15 May 2010).

9 Hackler RH. Long-term suprapubic cystostomy drainage in spinal cord injury patients. Br J Urol 1982; 54: 120-121.

10 Lamid S. Long-term follow-up of spinal cord injury patients with vesicoureteral reflux. Paraplegia 1988; 26: 27-34.

11 Hall MK, Hackler RH, Zampieri TA, Zampieri JB. Renal calculi in spinal cord-injured patient: association with reflux, bladder stones, and Foley catheter drainage. Urology 1989; 34: 126-128.

12 Broecker $\mathrm{BH}$, Klein FA, Hackler RH. Cancer of the bladder in spinal cord injury patients. J Urol 1981; 125: 196-197.

13 Ginsberg DA, Rovner ES, Raz S. Complications of urinary diversion. In: Taneja S, Smith RB and Ehrlich R (eds) Complications in Urologic Surgery. WB Saunders: Philadelphia, USA, 2001, pp 454-467.

14 McGuire EJ, Woodside JR, Borden TA, Weiss RM. Prognostic value of urodynamic testing in myelodysplastic patients. J Urol 1981; 126: 205-209.

15 Leng WW, Faerber G, Del Terzo M, McGuire EJ. Long-term outcome of incontinent ileovesicostomy management of severe lower urinary tract dysfunction. J Urol 1999; 161: 1803-1806.

16 Jayanthi VR, Churchill BM, McLorie GA, Khoury AE. Concomitant bladder neck closure and Mitrofanoff diversion for the management of intractable urinary incontinence. J Urol 1995; 154: 886-888.

17 Hensle TW, Kirsch AJ, Kennedy WA, Riley EA. Bladder neck closure in association with continent urinary diversion. J Urol 1995; 154: 883-885.

18 Hoebeke P, De Kuyper P, Goeminne H, Van Laecke E, Everaert K. Bladder neck closure for treating pediatric incontinence. Eur Urol 2000; 38: 453-456.

19 Tan HJ, Stoffel J, Daignault S, McGuire EJ, Latini JM. Ileovesicostomy for adults with neurogenic bladders: complications and potential risk factors for adverse outcomes. Neurourol Urodyn 2008; 27: 238-243.

20 Schwartz SL, Kennelly MJ, McGuire EJ, Faerber GJ. Incontinent ileovesicostomy urinary diversion in the treatment of lower urinary tract dysfunction. J Urol 1994; 152: 99-102. 